\title{
Chronic Restraint Stress Induces Gastric Mucosal Inflammation with Enhanced Oxidative Stress in a Murine Model
}

This article was published in the following Dove Press journal: Psychology Research and Behavior Management

\author{
Maimaiti Yisireyili ${ }^{1,2}$ \\ Aziguli Alimujiang' \\ Aikebaier Aili ${ }^{1,2}$ \\ Yiliang $\mathrm{Li}^{2}$ \\ Salamaiti Yisireyili' \\ Kelimu Abudureyimu (DD) ${ }^{1,2}$ \\ 'Research Institute of General and \\ Minimally Invasive Surgery, People's \\ Hospital of Xinjiang Uygur Autonomous \\ Region, Urumqi, Xinjiang 83000I, \\ People's Republic of China; ${ }^{2}$ Department \\ of Minimally Invasive Surgery, Hernia, and \\ Abdominal Wall Surgery, People's \\ Hospital of Xinjiang Uygur Autonomous \\ Region, Urumqi, Xinjiang 83000 I, \\ People's Republic of China
}

Background: Although the underlying mechanisms of chronic stress are still unknown, this condition has been related to the pathophysiology of gastric mucosal inflammation, whose development is accelerated by oxidative stress. The present study investigates how chronic stress influences gastric mucosal oxidative stress and inflammation.

Methods: Eight-week-old C57BL/6J male mice were subjected to two-week intermittent restraint stress. The expressions of CD11b (a specific for monocyte/macrophage), monocyte/ macrophage cell surface markers (CD68 and F4/80), NADPH oxidase-4 (Nox-4) and 8-hydroxy-2'-deoxyguanosine (8-OHdG, a sensitive biomarker of oxidative stress) were determined using immunohistochemistry, RT-PCR, and enzyme-linked immunosorbent assay, respectively. The expressions of antioxidant enzymes, such as superoxide dismutase, catalase, and glutathione peroxidase, were examined by RT-PCR and Western blotting. The expressions of proinflammatory cytokines, including monocyte chemoattractant protein-1 (MCP-1), interleukin-1 $\beta$ (IL-1 $\beta$ ), and tumor necrosis factor- $\alpha$ (TNF- $\alpha$ ), were determined using immunohistochemistry and RT-PCR, respectively.

Results: Chronic stress increased the lymphocytic infiltration and inflammation within the gastric mucosa of mice. Stress remarkably increased the expression levels of CD11b and mRNA expression levels of CD68 and F4/80 in the mucosa of the stomach of stressed mice. Stress remarkably increased both mRNA and plasma concentrations of Nox-4 and 8-OHdG; and markedly reduced gastric mRNA and protein expression levels of antioxidant enzymes such as superoxide dismutase, catalase, and glutathione peroxidase. The expressions of proinflammatory cytokines (MCP-1, IL-1 $\beta$, and TNF- $\alpha$ ) were predominantly observed in the gastric mucosal layers of the stressed mice. Furthermore, stress remarkably elevated the gastric mucosal mRNA expression levels of MCP-1, IL-1 $\beta$, and TNF- $\alpha$.

Conclusion: Two weeks of restraint stress induced gastric inflammation in the murine model with enhanced oxidative stress and reduced anti-oxidative system.

Keywords: stress, oxidative stress, anti-oxidative proteins, gastric mucosal inflammation

\section{Introduction}

Psychoneuroimmunological studies revealed that the activation of the sympathetic nerve system and hypothalamic pituitary-adrenal axis (HPA) promotes the secretion of adrenal systemic catecholamines and glucocorticoid to alternate systemic, hormonal, and immune response. ${ }^{1}$ Chronic psychological stress in the modern lifestyle is closely linked to the incidence of metabolic syndrome (MetS), diabetes mellitus, and gastroesophageal reflux diseases (GERDs). ${ }^{2}$ Chronic psychological stress is
Correspondence: Kelimu Abudureyimu Department of Minimally Invasive Surgery, Hernia, and Abdominal Wall Surgery, People's Hospital of Xinjiang Uygur Autonomous Region, 9I Tianchi Road, Tianshan District, Urumqi, Xinjiang 83000I, People's Republic of China Email kelimu6075@sina.com 
triggered when various psychological, physiological, or environmental stressors provoke a sense of threatened homeostasis. This condition was identified as a risk factor in $75-90 \%$ of all diseases, including those that lead to morbidity and mortality. ${ }^{3}$

Stress-induced gastric mucosal lesion (SGML) is characterized by gastric mucosal hemorrhage, ulcer, and erosion, which occur under severe trauma, exhaustive exercise, and acute or chronic types of psychological stress. ${ }^{4}$ SGML is caused by the disruption of the balance between the CNS and the brain-gut peptides of the gastric mucosa. Chronic psychological stress affects the autonomic nervous system and HPA axis, thereby aggravating the gastric mucosal ulcer and erosion. ${ }^{5}$ Psychological stress in modern work and lifestyle is closely related to the incidence of SGML. ${ }^{6}$

The production of reactive oxygen species (ROS), which are neutralized by enzymatic and non-enzymatic antioxidant defense systems, is a key mechanism of chronic stress. ${ }^{6}$ Among the several types of stress (eg, acute and episodic acute), chronic stress can ruin the balance between the ROS production and antioxidant responses of cells, thereby disrupting metabolic regulation and causing oxidative damage. ${ }^{7}$ Chronic stress can also be classified into several types (eg, restraint stress and chronic heterotypic stress) that lead to the production of oxidative stress in various parts of the human body, including the brain, lungs, heart, kidney, and gastrointestinal system. ${ }^{8,9}$ Chronic stress modifies the expression of a generegulating antioxidant system and NADPH oxidase (Nox), which is a major driver of ROS production in many types of cells. $^{10-15}$ Nox-induced ROS is the main source of oxidative stress that accelerates the progression of various inflammatory diseases, including adipose, ${ }^{11}$ intestinal, ${ }^{12}$ and esophageal inflammation. ${ }^{13}$

Considering the limited research on gastric inflammation, this study investigates how chronic stress triggers gastric inflammation by observing rodents placed under chronic restraint stress.

\section{Materials and Methods}

\section{Experimental Animals}

A total of thirty 8-week-old male $\mathrm{C} 57 \mathrm{BL} / 6 \mathrm{~J}$ mice were obtained from the Animal Center of Xinjiang Medical University (Urumqi, China). Animals were housed (one per cage) under standard conditions of $21-25^{\circ} \mathrm{C}$ and $50 \pm 5 \%$ humidity with a $12 \mathrm{~h} / 12 \mathrm{~h}$ light/dark cycle (lights on at 8:30 a.m.) in a specific-pathogen-free facility in the Research Institute of Uygur Pharmaceutics (Urumqi, China). All mice were provided with tap water and a normal chow diet (Teklad Diet; $18 \%$ fat, $24 \%$ protein, $58 \%$ carbohydrates). The study protocol was approved by the Animal Care and Use Committee of the People's Hospital of Xinjiang Uygur Autonomous Region (protocol no. KY201803703; Urumqi, China). The study was completed based on the Guidelines for the Care and Use of Laboratory Animals published by the National Institutes of Health.

\section{Restraint Stress Protocol}

The mice were equally and randomly divided into control and stress groups ( $\mathrm{n}=15$ each group). The mice in the control group were left undisturbed and placed in individual cages. Restraint stress was performed using a $50 \mathrm{~mL}$ plastic tube. The mice in the stress group were placed in a self-made restraint device. A centrifugal tube $(50 \mathrm{~mL})$ was scalded along the right and left tube walls to produce several ventilation holes (approximately $5 \mathrm{~mm}$ in diameter) for maintenance of breathing. A small hole was made in tube lid to let the tail out of the tube. The mice in the stress group underwent immobilization stress for $2 \mathrm{~h}$ (between 10:00 a.m. and 12:00 p.m.) each day for 14 consecutive days. ${ }^{10-14}$ During the stress period (immobilizing for $2 \mathrm{~h}$ ) the mice were not supplied with water and food, after which they were placed back to their individual cages and supplied with food and water freely. Body weight and food intake were monitored every 2 days during the stress period.

\section{Sample Collections}

All mice underwent a $16-18 \mathrm{~h}$ fasting period, were anesthetized with $150 \mathrm{mg} / \mathrm{kg}$ intraperitoneal sodium pentobarbital, and euthanized the morning after the last day of the stress period. Blood samples were collected from the inferior vena cava of the euthanized mice for biological analysis. Tissue samples were also collected from the mice to examine their pathology, extract their total RNA, and analyze the expression levels of their biological markers.

\section{Histopathology}

The stomach tissues collected from the euthanized mice were excised, weighed, fixed with $10 \%$ formalin, and dehydrated with ethanol at room temperature before embedding in paraffin. The embedded tissues were then cut into $4 \mu \mathrm{m}$ sections and stained with H\&E. A digital camera (Eclipse E200; Nikon, Tokyo, Japan) was used to randomly capture photos of the H\&E staining per section 
of the embedded tissues under $200 \times$ light microscopy from 10 microscopic fields. The stress-induced inflammatory damages were evaluated by histologic scoring performed by an investigator who was blinded to the group. For statistics, each individual score represented the mean of the three sections. The histologic findings were scored as follows: ${ }^{16}$

1. mucosal edema (score 0-4), (2) hemorrhage (score $0-4),(3)$ inflammatory cell infiltration (score $0-3$ ), and (4) epithelial cell loss (score $0-3$ ).

\section{Immunohistochemistry}

The streptavidin-biotinylated peroxidase complex methods described in our previous studies were employed in immunohistochemistry. ${ }^{10-15}$ All sections of the extracted stomach tissue from each mouse were deparaffinized with xylene prior to dehydration with a series of ethanol treatments. These tissues were then incubated overnight at $4{ }^{\circ} \mathrm{C}$ with primary antibodies, including anti-CD11b (1:100; ab133357, Abcam, Cambridge, UK), anti-CD68 (1:200; ab125212, Abcam, Cambridge, UK), anti-F4/80 (1:100, sc-377009, Santa Cruz Biotechnology, Inc. TX, USA), anti-Nox-4 (1:100; ab133303, Abcam, Cambridge, UK), anti-8-OHdG $(1 \mu \mathrm{g} / \mathrm{mL}$; Japan Institute for the Control of Aging, Fukuroi, Japan), anti-MCP-1 (1:100; sc-32771, Santa Cruz Biotechnology, Inc. TX, USA), anti-IL-1 $\beta$ (1:200; \#12242; Cell Signaling Technology, Inc. MA, USA), and anti-TNF- $\alpha$ (1:100; ab6671, Abcam, Cambridge, UK). Exactly $30 \mathrm{mg} / \mathrm{mL}$ of 3,3-diaminobenzidine tetra-hydrochloride tablet (Merck KGaA, Darmstadt, Germany) with $0.03 \% \mathrm{H}_{2} \mathrm{O}_{2}$ was then used to visualize the localization of CD11b, CD68, F4/80, Nox-4, 8-OHdG, MCP-1, IL-1 $\beta$, and TNF- $\alpha$. Then, sections were counterstained with $2 \%$ methylene green for $12 \mathrm{~min}$. The sections were dehydrated again, cleared in xylene, and mounted in mounting media (Mount-quick, Daydo Sangyo Co., Saitama, Japan). Images of all sections were captured under a light microscope (magnification, $\times 200$ ) with a digital camera (Eclipse E200; Nikon Corporation). The CD11b-positive cells in 10 randomly selected microscopic fields per section in mice stomach were determined using Adobe Photoshop and quantified using ImageJ $1.45 \mathrm{~S}$.

\section{Quantitative RT-PCR}

Total RNA was extracted from the stomach tissues of mice by using TRIzol reagent (Thermo Fisher Scientific, Inc. MA, USA) and subjected to RT (Qiagen, Hilden, Germany). Total RNA ( $1 \mu \mathrm{g})$ was reverse transcribed to cDNA with oligo (dT) primers with the RT system based on the manufacturer's directions. The obtained cDNA was subjected to $\mathrm{qPCR}$ analysis with the following cycling parameters: $2 \mathrm{~min}$ initial denaturation at $95^{\circ} \mathrm{C}$ followed by 40 cycles of $12 \mathrm{~s}$ at $95^{\circ} \mathrm{C}$ and $60 \mathrm{~s}$ at $60^{\circ} \mathrm{C}$ by using the Bio-Rad CFX96 Touch Real-Time PCR detection system (Bio-Rad Laboratories, Inc., Hercules, CA, USA) and Power SYBR Green PCR Master Mix (Applied Biosystems; Thermo Fisher Scientific, Inc.MA, USA). Serial dilutions of a control sample of cDNA were used to generate the standard curve for each reaction. All experiments were performed in triplicate. Changes in gene expression were calculated by the $2^{-\Delta \Delta \mathrm{CT}}$ method. ${ }^{17}$ The values were normalized to the levels of $\beta$-actin. Table 1 presents the sequences of primers used in this study. Each RNA amount was also normalized to its corresponding $\beta$-actin mRNA amount.

Table I Sequences of Primers Used for the RT-PCR Experiment

\begin{tabular}{|c|c|c|c|}
\hline Gene & Forward (5'-3') & Reverse (5'-3') & Size \\
\hline CD68 & ACTTCGGGCCATGTTTCTCT & GGCTGGTAGGTTGATTGTCGT & 139 \\
\hline $\mathrm{F} 4 / 80$ & CTTTGGCTATGGGCTTCCAGTC & GCAAGGAGGACAGAGTTTATCGTG & 165 \\
\hline Nox-4 & САССTCTGCCTGCTCATTTGG & AGTTGAGGTTCAGGACAGATGC & 153 \\
\hline$M n-S O D$ & CACATTAACGCGCAGATCATG & CCAGAGCCTCGTGGTACTTCTC & 100 \\
\hline $\mathrm{Cu}, \mathrm{Zn}-\mathrm{SOD}$ & CAGCATGGGTTCCACGTCCA & CACATTGGCCACACCGTCCT & 168 \\
\hline$G P x$ & GGGCAAGGTGCTGCTCATTG & AGAGCGGGTGAGCCTTCTCA & 269 \\
\hline Catalase & CCAGCGACCAGATGAAGCAG & ССАСТСТСTCAGGAATCCGC & 198 \\
\hline$M C P-I$ & TCAGCCAGATGCAGTTAACGC & TGATCCTCTTGTAGCTCTCCAGC & 95 \\
\hline$I L-I \beta$ & AACCTGCTGGTGTGTGACGTTC & CAGCACGAGGCTTTTTTTGTTGT & 78 \\
\hline$T N F-\alpha$ & AGGCTGCCCCGACTACGT & GACTTTCTCCTGGTATGAGATAGCA & 70 \\
\hline$\beta$-actin & TATTGGCAACGAGCGGTTC & ATGCCACAGGATTCCATACCC & 75 \\
\hline
\end{tabular}




\section{Western Blotting}

Total protein was extracted from stomach tissue $(\sim 30 \mathrm{mg})$ using lysis buffer [ $65 \mathrm{mmol} / 1$ Tris-HCl $(\mathrm{pH} 6.8), 3.3 \%$ SDS, $10 \%$ glycerol, $2.2 \%$ bromophenol blue]. The protein concentration was determined using the BCA protein assay kit (Pierce, Rockford, IL, USA). Then, the equal amount of protein $(50 \mu \mathrm{g})$ for each sample was separated via SDS-PAGE on a $10 \sim 15 \%$ of polyacrylamide gel. The separated proteins were transferred onto polyvinylidene difluoride membranes and blocked for $1 \mathrm{~h}$ at room temperature with $5 \%$ bovine serum albumin (Cat no: 10735078001 (50 g), Sigma-Aldrich; Merck KGaA) in Tris-buffered saline containing Tween ${ }^{\circledR}-20$ (TBS-T). Membranes were washed with TBS-T, and incubated with primary antibodies against $\mathrm{Mn}$ SOD (Cat no: MAB10394, Abnova, Taiwan), Cu, Zn SOD (Cat no: AF3418, R\&D System, USA), Catalase (Cat no:ab52477, Abcam, UK), and GPx (Cat no:ab59524, Abcam, UK) and $\beta$-actin (Cat no: \#3700, Cell Signaling Technology, USA) (all these antibodies dilution rate was 1:1000). Following primary antibody incubation, membranes were further incubated with horseradish peroxidase-linked anti-mouse antibody (Cat no: \#7076, Cell Signaling Technology, USA) and anti-rabbit antibody (Cat no: \#7074, Cell Signaling Technology, USA) $(1: 10,000)$ for $1 \mathrm{~h}$ at room temperature. Membranes were then washed three times with TBS-T. Protein bands were visualized using the enhanced Chemi-Lumi One System (Nacalai Tesque, Inc).

\section{ELISA Assays}

Plasma samples were obtained from all mice and processed as previously described. ${ }^{10-14}$ The plasma levels of Nox4 (cat no; SEB924Mu, Cloud-Clone Corp.), a competitive ELISA kit, was used to determine the Nox-4 levels following the manufacturer's instructions. Plasma 8-OHdG levels were determined using a competitive ELISA kit (8-OHdG Check, cat no; KOG-200SE, highly sensitive kit, Japan Institute for the Control of Aging).

\section{Statistical Analysis}

All data were expressed as mean $\pm \mathrm{SD}$. Student's $t$-test was performed to measure the differences between the stress and control groups. Fisher's protected least significant difference test of ANOVA was also performed to analyze the quantitative data collected from both groups. A $p$ value of $<0.05$ was used to denote significance.

\section{Results}

\section{Stress Induced Gastric Mucosal Inflammation in Mice}

Eight-week-old male $\mathrm{C} 57 \mathrm{BL} / 6 \mathrm{~J}$ mice were randomly assigned to either the control or stress group. H\&E staining results revealed that stress increased the neutrophil (as shown in asterisks) and lymphocyte (as shown in arrows) infiltration into the lamina propria and glandular epithelium of the gastric mucosa and the inflammation within the gastric mucosa of the stressed mice (Figure 1A). The histopathological damage score of the stress group was remarkably higher than the control group (Figure 1B).

\section{Stress Induced Expression of Gastric Monocyte/Macrophage Markers in Mice}

Stress markedly increased the expression levels of CD11b (a specific for monocyte/macrophage) and levels of monocyte/ macrophage cell surface markers (CD68 and F4/80) in the mucosa of the stomach of stressed mice (Figure 2A-C). The CD11b-positive cells in the stomach of the stressed mice also remarkably increased compared with those in the control mice (Figure 2D). Furthermore, 2 weeks of restraint stress substantially upregulated the mRNA expression levels of CD68 and F4/80, as shown in Figure 2E and F.

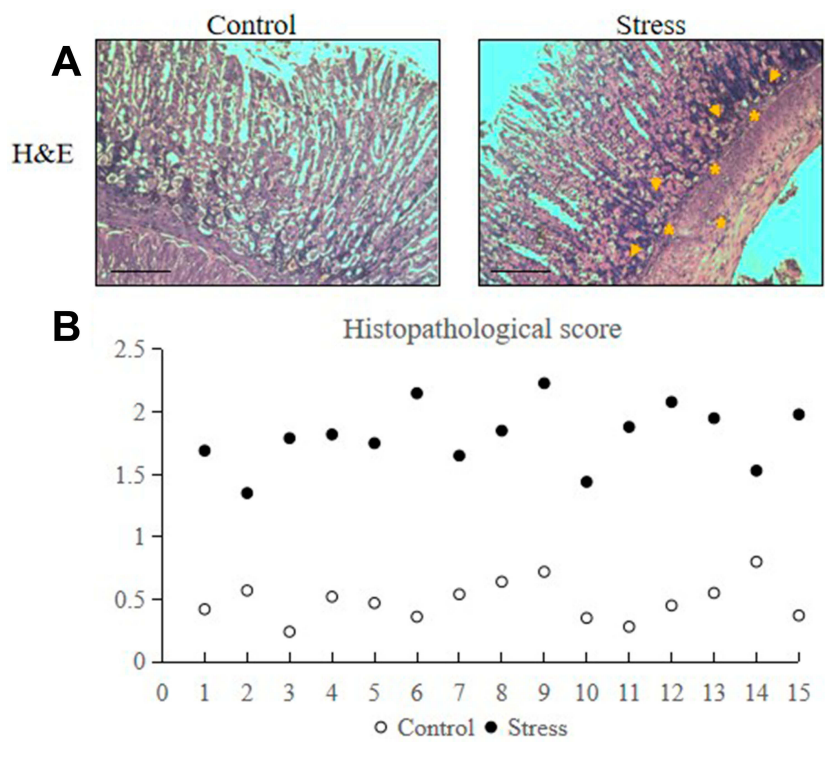

Figure I Stress induced gastric mucosal inflammation in mice. The mice were placed under immobilization stress for $2 \mathrm{~h}$ per day for 2 weeks. Stomach tissues were extracted from the stressed and control mice and were analyzed via H\&E staining. The values for the stressed mice are presented in comparison with those of the control mice and are expressed as mean $\pm S D(n=15)$. Dot-plot and median were used to test the differences between the stress and control groups. (A) Accumulation of neutrophils (as shown in asterisks) and lymphocytes (as shown in arrows) in stomach tissues following 2 weeks of restraint stress (200x magnification, bar=50 $\mu \mathrm{m}$ ). (B) Histopathological score of control and stressed mice. 

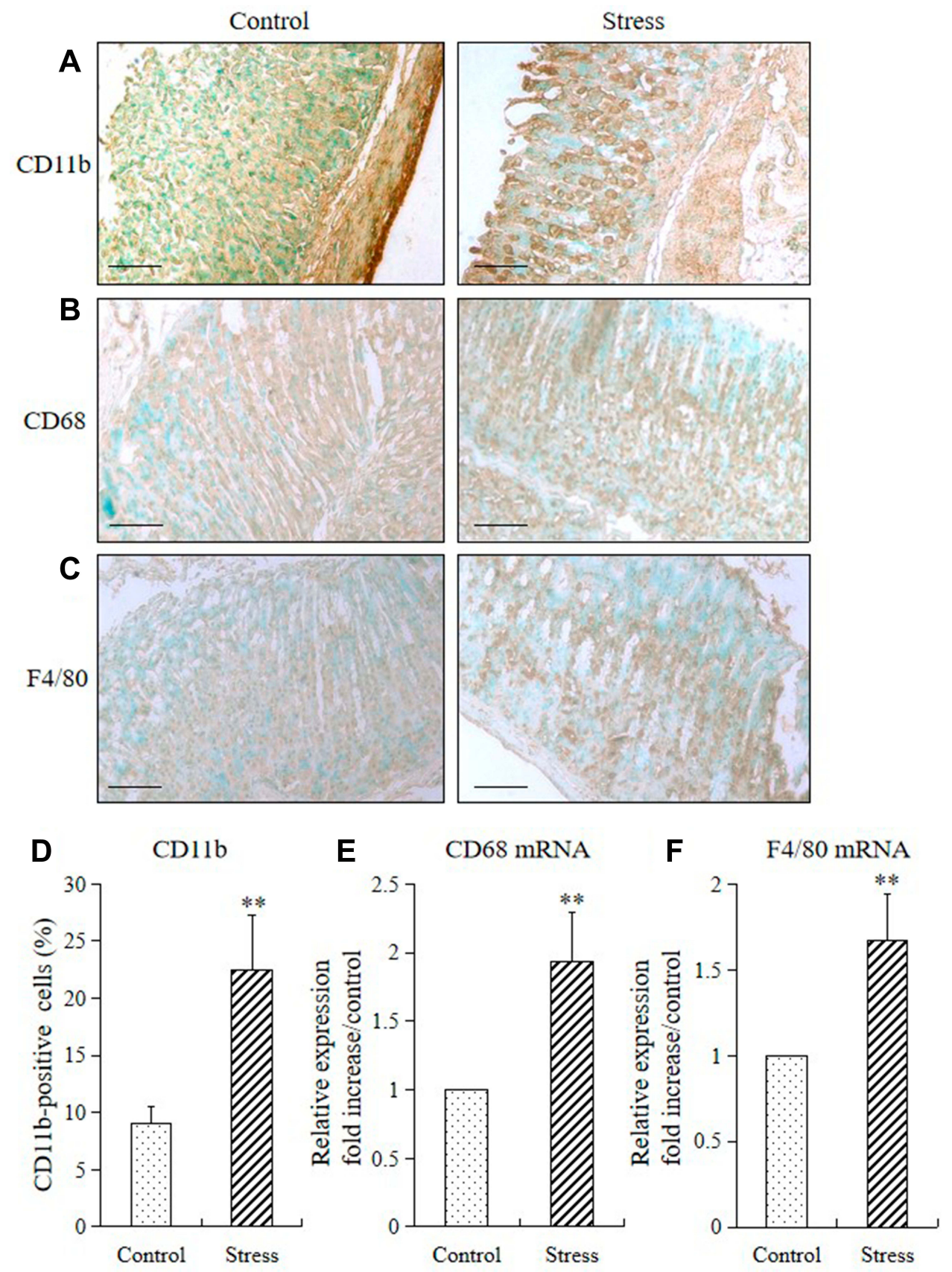

Figure 2 Stress induced expression of gastric monocyte/macrophage markers in mice. The immunohistochemistry and RT-PCR method were used to analyze the immunostaining and mRNA expression levels of CDI lb, CD68, and F4/80 in the stomach of mice in the stress and control groups. The values for the stressed mice are presented in comparison with those of the control mice and are expressed as mean $\pm S D(n=15)$. Student's $t$-test was performed to test the differences between the stress and control groups. (A) CDI Ib-positive cells (monocytes), (B) CD68, and (C) F4/80 in the stomach tissue of both control and stressed mice (200x magnification, bar=50 $\mu \mathrm{m})$; (D) quantitative analysis of CDI lb-positive cells relative to the total number of nuclei. $* * P<0.00 \mathrm{I}$ compared with the control mice; (E) quantitative analysis of $\mathrm{CD} 68$ mRNA and (F) F4/80 mRNA expression levels in stomach tissue. $* * P<0.001$ compared with the control mice.

\section{Stress Increased Gastric ROS Production in Mice}

We performed immunohistochemistry, RT-PCR, and ELISA to analyze the expressions of NADPH oxidase-4 (Nox-4) and 8-OHdG (a sensitive biomarker of oxidative stress) in mice and to determine whether stress also increases the generation of ROS in the stomach tissue. Subjecting the mice to 2 weeks of restraint stress remarkably increased the Nox-4 and $8-\mathrm{OHdG}$ in the mucosa of the stomach (Figure $3 \mathrm{~A}$ and $\mathrm{B}$ ), upregulated the Nox-4 mRNA expression (Figure 3C), and increased their Nox-4 and 8-OHdG plasma levels (Figure 3D and E). 

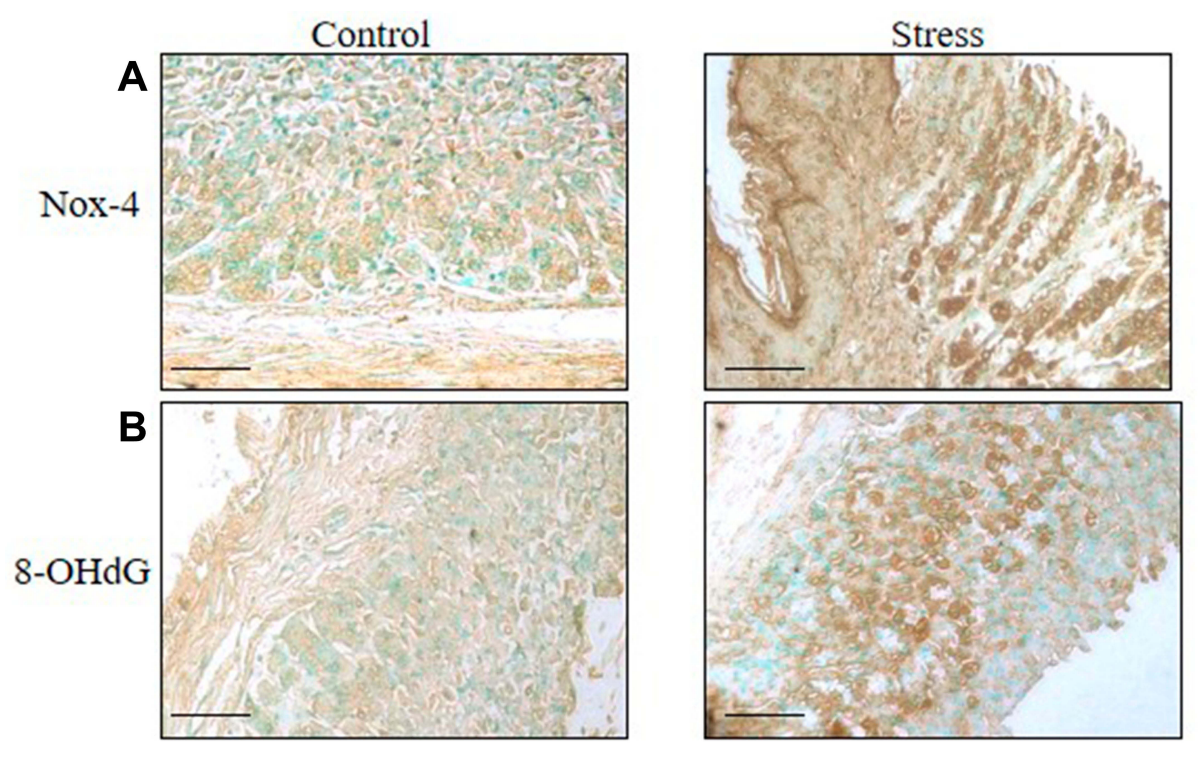

C Nox-4 mRNA
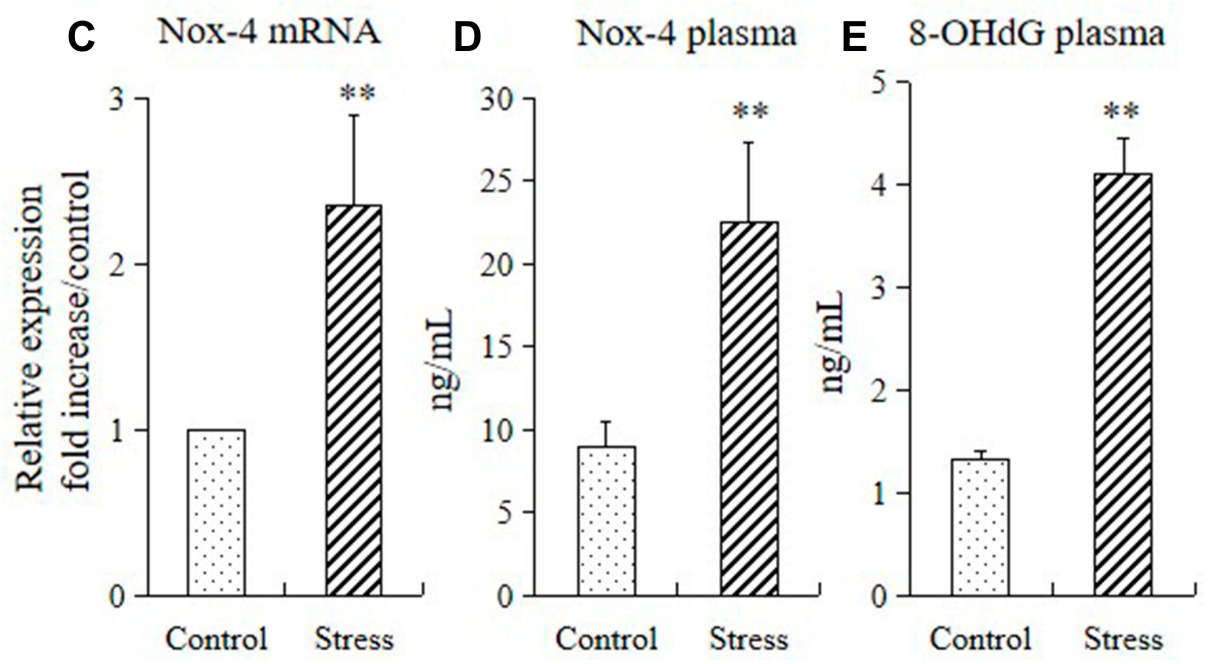

Figure 3 Stress increased gastric ROS production in mice. Immunohistochemistry, quantitative PCR, and ELISA were performed to check the expression levels of ROS biomarkers (Nox-4 and 8-OHdG) in the stomach of mice in the stress and control groups. The values for the stressed mice are presented relative to those for the control mice and are expressed as mean \pm SD $(n=15)$. Student's $t$-test was performed to analyze the differences between the stress and control groups. (A) Immunostaining of Nox4 in the stomach tissue (200x magnification, bar $=50 \mu \mathrm{m})$; (B) immunostaining of 8-OHdG in the stomach tissue $(200 \times$ magnification, bar $=50 \mu \mathrm{m})$; $(\mathbf{C})$ quantitative analysis of Nox-4 mRNA expression levels in stomach tissue. ${ }^{* * P}<0.001$ compared with the control mice; (D) plasma concentrations of Nox-4 and (E) 8-OHdG in the control and stressed mice. $* * P<0.001$ compared with the control mice.

\section{Stress Decreased the Gastric Expression of Antioxidants in Mice}

Considering that oxidative stress damages the function of the epithelial barrier in the gastrointestinal system, in this study we examined the role of antioxidants [superoxide dismutase (SOD), $\mathrm{Cu}, \mathrm{Zn}$ SOD $(\mathrm{Cu}, \mathrm{Zn}$ SOD), catalase (CAT), and glutathione peroxidase (GPx)] in gastric mucosal lesions by subjecting mice to restraint stress. We examined the mRNA and protein expression of these enzymes in the stomach of mice in the control and stressed group. The 2 weeks of restraint stress resulted in substantial downregulations of gastric
Mn-SOD, $\mathrm{Cu}, \mathrm{Zn}-\mathrm{SOD}, \mathrm{CAT}$, and GPx mRNA and protein expression (Figure 4A-E).

\section{Stress Induced Gastric Inflammatory Cytokine Expression in Mice}

We performed immunohistochemistry and quantitative RT-PCR to analyze the proinflammatory cytokine (MCP-1, IL-1 $\beta$, and TNF- $\alpha$ ) expression in mice and determine whether stress also provokes cytokine expression in the stomach tissue. Immunohistochemistry result showed that the expressions of monocyte chemoattractant protein-1 (MCP-1; Figure 5A), interleukin-1 $\beta$ (IL-1 $\beta$; Figure 5B), 

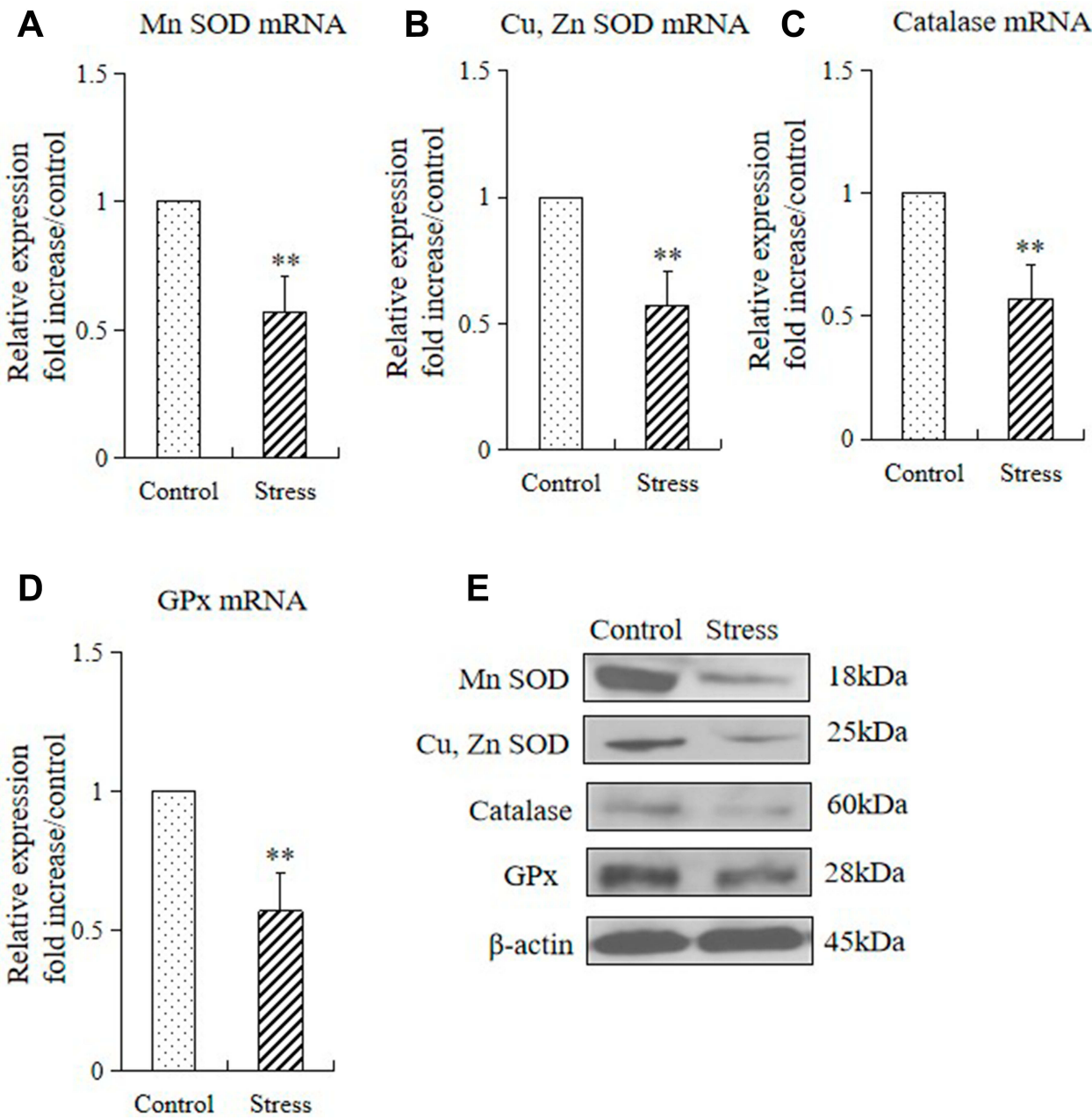

\section{E}

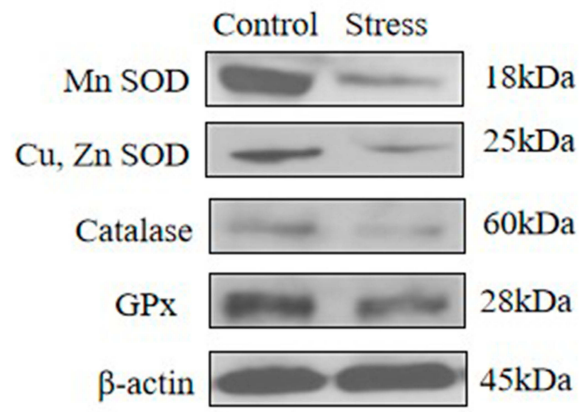

Figure 4 Stress decreased the gastric expressions of antioxidants in mice. The mRNA and protein expression levels of antioxidant enzymes in the stomach tissue of control mice and stressed mice were analyzed by quantitative RT-PCR and Western blot, respectively (A-E). The values for the stress mice are presented in comparison with those for the control mice and are expressed as mean $\pm S D(n=15)$. Student's $t$-test was performed to test the differences between the stress and control groups. (A) Quantitative analysis of Mn SOD mRNA, Cu, Zn SOD mRNA (B), catalase mRNA (C), and GPx mRNA (D) expression levels in stomach tissue; (E) protein expressions of Mn SOD, Cu, $\mathrm{Zn}$ SOD, catalase, and GPx in stomach tissue of control and stressed mice. $* * P<0.00 \mathrm{I}$ compared with the control mice.

and tumor necrosis factor- $\alpha$ (TNF- $\alpha$; Figure 5C) were predominantly observed in the mucosal layers of the stomach. RT-PCR results showed that 2 weeks of restraint stress resulted in a substantial increase in the mRNA expression of gastric MCP-1, IL-1 $\beta$, and TNF- $\alpha$ (Figure 5D-F).

Overall, the above-mentioned findings suggest that 2 weeks of restraint stress resulted in gastric mucosal inflammation via ROS production and reduced expression levels of antioxidants.

\section{Discussion}

The present study provided several novel findings. First, chronic stress induced gastric inflammation in mice accompanied by monocyte/lymphocytic infiltration, ROS over generation, and elevated proinflammatory cytokine expression (MCP-1, IL-1 $\beta$, and TNF- $\alpha$ ). Second, chronic restraint stress induced oxidative stress as reflected in the expression of Nox4 and 8-OHdG in mice. Third, chronic stress reduced the expression of anti-oxidative enzymes (Mn-SOD, Cu, Zn-SOD, catalase, and GPx) in the stomach of stressed mice. Stress triggered gastric inflammation by enhancing oxidative stress and suppressing the anti-oxidative system.

A systemic response occurs when the body is stimulated by psychological, environmental, and physiological stressors. Stress can activate various stress pathways, including the HPA axis and sympathetic nervous system (SNS), as well as elicit physiological responses, resulting in stress-related disorders. The gastrointestinal system is especially vulnerable to acute or chronic stress, as demonstrated by the stress-induced changes in gastric acid secretion, motility, mucosal permeability, barrier function, and 

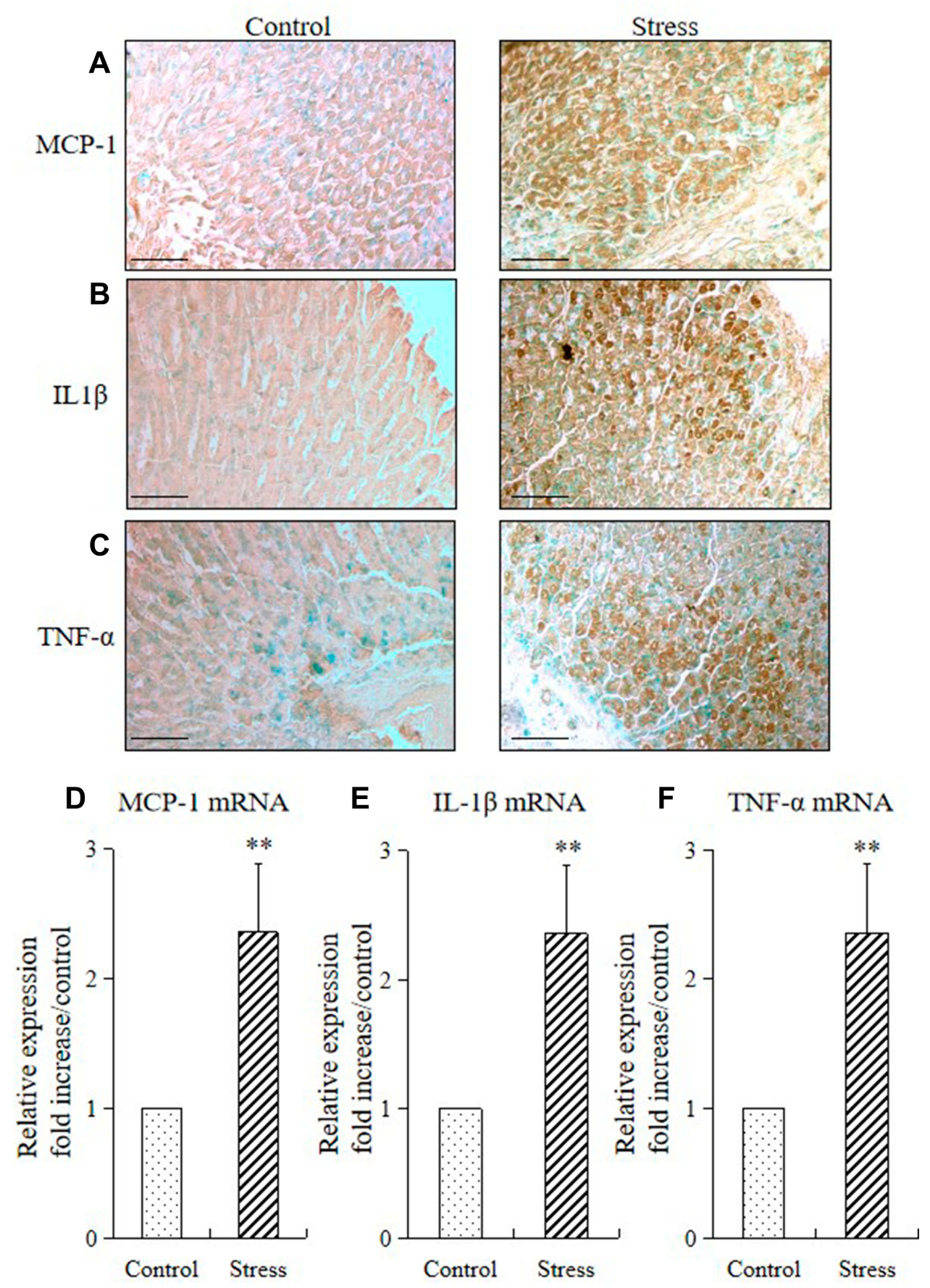

Figure 5 Stress induced gastric inflammatory cytokine expression in mice. Immunohistochemistry and quantitative RT-PCR were performed to analyze the immunostaining and mRNA expression levels of inflammatory cytokines (MCP-I, ILI $\beta$, and TNF- $\alpha$ ) in the stomach of the stressed and control mice. The values for the stressed mice are presented relative to those for the control mice and are expressed as mean \pm SD $(n=15)$. Student's $t$-test was performed to analyze the differences between the stress and control groups. Immunostaining of (A) MCP-I, (B) ILI $\beta$, and (C) TNF- $\alpha$ in the stomach tissue of control and stressed mice $(200 \times$ magnification, bar $=50 \mu \mathrm{m})$; quantitative analysis of (D) MCP-I mRNA, (E) ILI $\beta$ mRNA, and (F) TNF- $\alpha$ mRNA expression levels in stomach tissues. $* * P<0.001$ compared with the control mice.

visceral sensitivity. ${ }^{18}$ Studies reported that serum levels of adrenocorticotropin hormone, corticosteroids, and adrenaline increases in response to water-immersion restraint stress (WIRS) stimulation in rodents. ${ }^{19}$ The chronic exposure to restraint stress would exert significant impacts on the physiological function of the stomach, and that such impacts would lead to changes in gastric secretory activities. Furthermore, activation of the sympathetic nervous system due to stress exposure and splanchnic vasoconstriction due to increased catecholamine secretion from the adrenal gland lead to increase blood flow to the visceral organs, including the stomach. ${ }^{20}$ Chronic stress stimulates 
the release of sympathetic-adrenal corticosteroids, which leads to excessive gastric acid secretion, and inflammatory damage that eventually cause gastric ulcers. ${ }^{21}$ Chronic stress also increases the concentration of catecholamine in blood, constricts the blood vessels of gastric mucosa, and substantially decreases blood flow, which leads to gastric mucosal ischemia and hypoxia. ${ }^{22,23}$ Chronic stress leads to SGML, especially in depression and anxiety, which are closely related to the increased risk of SGML. ${ }^{24}$

Patients with SGML often suffer from the sudden onset of pain on the right side of the upper abdomen, which is characterized by swelling or burning pain, mostly intermittent, paroxysmal aggravation, inflammation, or ulcer of the gastric mucosa. ${ }^{25}$ The etiology of gastric lesion and ulcer is influenced by various aggressive and defensive factors such as acid pepsin secretion, parietal cells, mucosal barrier, mucous secretion, blood flow, cellular regeneration, endogenous productive agents (PGS and epidermic growth factors), and Helicobacter pylori ( $\mathrm{H}$. Pylori). However, it has been suggested that free radicals are closely related to peptic ulcer and gastritis. Oxygen free radicals are detrimental to the integrity of biological tissues and mediate their injury. The radicals also promote mucosal damage by causing degradation of the epithelial basement membrane components, complete alteration of the cell metabolism and DNA damage. ${ }^{26}$ Stress is known to cause severe adverse effects in the human gastrointestinal tract including mucosal microbleedings and erosions or even gastric ulceration, but the mechanism of these complications has not been fully elucidated. The pathogenesis of stress-induced gastric damage involves the fall in gastric blood flow, an increase in gastric acid secretion and gastric motility, enhanced adrenergic and cholinergic nerve activity and the rise in the gastric mucosal generation of reactive oxygen species. ${ }^{4}$ Mice exposed to restraint stress for 2 weeks showed neutrophil and lymphocyte infiltration and inflammatory changes in the lamina propria and glandular epithelium of gastric mucosa, as well as the proliferation of basal cells, thereby suggesting the occurrence of pathological changes after gastric mucosal injury (Figures 1 and 2). The scoring of chronic inflammation in the gastric mucosa of mice under chronic restraint stress was higher than in the control group, thereby indicating the occurrence of gastric mucosal injury caused by external factors and the response of repair.

The expression of antioxidant enzymes is influenced by amounts of free radicals and cytokines, such as TNF- $\alpha$ and IL-1 $\beta$. Pro- and anti-inflammatory mechanisms clearly depend on the type and intensity of stressors. ${ }^{3}$ Magierowski et $\mathrm{al}^{27}$ reported that gastric mucosal expression and plasma concentrations of interleukin-6 (IL-6), IL-1 $\beta$, TNF- $\alpha$, and interferon- $\gamma(\mathrm{IFN}-\gamma)$ were remarkably increased in the rat model of water immersion and restraint stress. Peng et $\mathrm{al}^{28}$ established a chronic stress model and reported that inflammatory cytokines, including TNF- $\alpha$, IL-18 and IL- $1 \beta$, were significantly increased in the experimental group after a 4-week period of stress. Furthermore, stress-induced inflammation of the adipose, colon, and esophageal tissues produces proinflammatory cytokines, including TNF- $\alpha$, IL-6, and $\mathrm{MCP}-1$, and exacerbates monocyte accumulation, thereby resulting in inflammatory damage to these tissues. $^{10-14}$ In the present study, the expression of MCP-1, IL- $1 \beta$, and TNF- $\alpha$ in the gastric mucosa was further detected by immunohistochemistry and RT-PCR. After 2 weeks of restraint stress, these proinflammatory cytokines were predominantly located in the entire mucosal layers of the stomach, and the mRNA expressions of MCP-1, IL-1 $\beta$, and TNF- $\alpha$ in the gastric mucosa were remarkably higher than those in the control group (Figure 5). Thus, the upregulation of the above proinflammatory cytokines confirmed the occurrence of gastric mucosal inflammation induced by psychological stress.

Oxidative stress is a key element in the pathogenesis of gastric mucosal injury/repair and the progression of gastric dysfunction. $^{29}$ NADPH oxidase, including Nox-4, is the primary producer of ROS in the stomach and plays key roles in remodeling and inflammation. ${ }^{30}$ Previously we reported that chronic restraint stress can trigger inflammation and ROS accumulation in different types of tissue. ${ }^{11-14}$ Oxidative stress also leads to esophageal fibrosis by increasing the TGF- $\beta 1$ expression, which in turn facilitates the synthesis of esophageal collagen and suppresses the degradation of collagen in the GERD animal model. ${ }^{10,31}$ In the present study, we demonstrated in vivo that subjecting mice to 2 weeks of restraint stress would enhance the gastric expression of Nox-4 and the biomarker of oxidative stress (8-OHdG; Figure 3).

Oxidative stress may result in the overproduction of ROS, inactivation of detoxification systems, consumption of antioxidants, and failure to adequately replenish antioxidants. $^{32,33}$ The antioxidant enzymes of the tissue are particularly important for the primary endogenous defense against the damaging actions of ROS. The enzymatic defense against ROS involves the cooperative action of three major intracellular antioxidant enzymes. The major defense against the toxicity of superoxide 
radicals is conferred by SOD. ${ }^{34}$ SOD catalyzes the dismutation of superoxide radicals that form hydrogen peroxide. GPx and CAT are the unique enzymes scavenging hydroperoxides, which act with SOD. Gastropathy is the result of neutrophil activation and subsequent release of ROS, such as superoxide anions $\left(\mathrm{O}_{2}{ }^{-}\right)$, hydroxyl radicals $\left(\mathrm{OH}^{-}\right)$, and hydrogen peroxide $\left(\mathrm{H}_{2} \mathrm{O}_{2}\right){ }^{35,36}$ Indeed, ROS are normally neutralized by efficient antioxidant systems in the body, including antioxidant enzymes, such as SOD, CAT, and GPx, and also by nutrient-derived, small antioxidant molecules, such as vitamin E, vitamin $\mathrm{C}$, carotenes, and flavonoid. ${ }^{34}$ Paulrayer et $\mathrm{al}^{37}$ showed that SOD and CAT could remarkably reduce the extent of gastric mucosal damage induced by aspirin. In the present study, we first demonstrated that 2 weeks of restraint stress resulted in substantial down-regulation of gastric antioxidants, such as Mn-SOD, Cu, Zn-SOD, CAT, and GPx (Figure 4). Our results suggested that gastric mucosal oxidation/antioxidant defense balance plays an important role in preventing SGML.

The current study involved a limitation in which we did not directly measure the amount of ROS production. Chronic restraint stress markedly induces the accumulation of ROS in the adipose tissues and in the colon. ${ }^{11,12}$ In the present study, we analyzed the expression ROS markers (Nox-4 and 8-OHdG) by using IHC, RT-PCR, and ELISA. Two weeks of restraint stress remarkably increased the Nox4 and 8-OHdG in the gastric mucosal and epithelial layers of mice and elevated the mRNA and circulatory concentrations of Nox-4 and 8-OHdG. Therefore, stress remarkably induced ROS production in mice stomach.

\section{Conclusion}

Two weeks of restraint stress induced gastric inflammation in the murine model, as well as enhanced oxidative stress and reduced the anti-oxidative system.

\section{Acknowledgments}

We thank Dr. Kyosuke Takeshita for carefully reading and applying changes to our manuscript.

\section{Author Contributions}

All authors contributed to data analysis, drafting or revising the article, gave final approval of the version to be published, and agree to be accountable for all aspects of the work.

\section{Funding}

This work, which was led by MY, supported by the Xinjiang Uygur Autonomous Region Natural Science Foundation Program (2018D01C134) and by Tianchi Hundred People Project for Introducing High-level Talents of Xinjiang Autonomous Region (201939).

\section{Disclosure}

The authors report no conflicts of interest in this work.

\section{References}

1. McEwen BS. Redefining neuroendocrinology: epigenetics of brain-body communication over the life course. Front Neuroendocrinol. 2018;49:8-30. doi:10.1016/j.yfrne.2017.11.001

2. Cheung BM, Li C. Diabetes and hypertension: is there a common metabolic pathway? Curr Atheroscler Rep. 2012;14(2):160-166. doi:10.1007/s11883-012-0227-2

3. Liu YZ, Wang YX, Jiang CL. Inflammation: the common pathway of stress-related diseases. Front Hum Neurosci. 2017;11:316. doi:10.3389/fnhum.2017.00316

4. Brzozowski T, Magierowska K, Magierowski M, et al. Recent advances in the gastric mucosal protection against stress-induced gastric lesions. Importance of renin-angiotensin vasoactive metabolites, gaseous mediators and appetite peptides. Curr Pharm Des. 2017;23(27):3910-3922. doi:10.2174/1381612823666170220160222

5. Guo S, Gao Q, Jiao Q, Hao W, Gao X, Cao JM. Gastric mucosal damage in water immersion stress: mechanism and prevention with GHRP-6. World J Gastroenterol. 2012;18(24):3145-3155. doi:10.3748/wjg.v18. i24.3145

6. De R, Mazumder S, Sarkar S, et al. Acute mental stress induces mitochondrial bioenergetic crisis and hyper-fission along with aberrant mitophagy in the gut mucosa in rodent model of stress-related mucosal disease. Free Radic Biol Med. 2017;113:424-438. doi:10.1016/j.freeradbiomed.2017.10.009

7. Verma S, Kumar VL. Attenuation of gastric mucosal damage by artesunate in rat: modulation of oxidative stress and NFKB mediated signaling. Chem Biol Interact. 2016;257:46-53. doi:10.1016/j. cbi.2016.07.027

8. Tomanek L. Proteomic responses to environmentally induced oxidative stress. J Exp Biol. 2015;218(Pt12):1867-1879. doi:10.1242/ jeb. 116475

9. Gutierrez J, Ballinger SW, Darley-Usmar VM, Landar A. Free radicals, mitochondria, and oxidized lipids: the emerging role in signal transduction in vascular cells. Circ Res. 2006;99(9):924-932. doi:10.1161/01.RES.0000248212.86638.e9

10. Yisireyili M, Wulamu W, Aili A, et al. Chronic restraint stress induces esophageal fibrosis with enhanced oxidative stress in a murine model. Exp Ther Med. 2019;18(2):1375-1383. doi:10.3892/etm.2019.7669

11. Yisireyili M, Takeshita K, Hayashi M, et al. Dipeptidyl peptidase- IV inhibitor alogliptin improves stress-induced insulin resistance and prothrombotic state in a murine model. Psychoneuroendocrinology. 2016;73:186-195. doi:10.1016/j.psyneuen.2016.08.004

12. Yisireyili M, Uchida Y, Yamamoto K, et al. Angiotensin receptor blocker irbesartan reduces stress-induced intestinal inflammation via AT1a signaling and ACE2-dependent mechanism in mice. Brain Behav Immun. 2018;69:167-179. doi:10.1016/j.bbi.2017.11.010

13. Wulamu W, Yisireyili M, Aili A, et al. Chronic stress augments esophageal inflammation, and alters the expression of transient receptor potential vanilloid 1 and protease-activated receptor 2 in a murine model. Mol Med Rep. 2019;19(6):5386-5396. doi:10.3892/ mmr.2019.10192 
14. Yisireyili M, Hayashi M, Wu H, et al. Xanthine oxidase inhibition by febuxostat attenuates stress-induced hyperuricemia, glucose dysmetabolism, and prothrombotic state in mice. Sci Rep. 2017;7(1):1266. doi:10.1038/s41598-017-01366-3

15. Yisireyili M, Shimizu H, Saito S, Enomoto A, Nishijima F, Niwa T. Indoxyl sulfate promotes cardiac fibrosis with enhanced oxidative stress in hypertensive rats. Life Sci. 2013;92(24-26):1180-1185. doi:10.1016/j.1fs.2013.05.008

16. Li W, Wang X, Zhi W, et al. The gastroprotective effect of nobiletin against ethanol-induced acute gastric lesions in mice: impact on oxidative stress and inflammation. Immunopharmacol Immunotoxicol. 2017;39(6):354-363. doi:10.1080/08923973.2017.1379088

17. Livak KJ, Schmittgen TD. Analysis of relative gene expression data using real-time quantitative PCR and the $2^{\Delta \Delta C T}$ method. Methods. 2001;25:402-408. doi:10.1006/meth.2001.1262

18. Yeomans ND. The ulcer sleuths: the search for the cause of peptic ulcers. J Gastroenterol Hepatol. 2011;26(Suppl1):35-41. doi:10.11 11/j.1440-1746.2010.06537.x

19. Ohta Y, Kaida S, Chiba S, et al. Involvement of oxidative stress in increases in the serum levels of various enzymes and components in rats with water- immersion restraint stress. J Clin Biochem Nutr. 2009;45(3):347-354. doi:10.3164/jcbn.09-59

20. Konturek PC, Brzozowski T, Konturek SJ. Stress and the gut: pathophysiology, clinical consequences, diagnostic approach and treatment options. J Physiol Pharmacol. 2011;62:591-599.

21. Qiao X, Yang J, Fei SJ, et al. Protective effect of histamine microinjected into cerebellar fastigial nucleus on stress gastric mucosal damage in rats. Brain Res. 2015;1629:351-360. doi:10.1016/j. brainres.2015.10.014

22. Wang T, Leng YF, Zhang Y, Xue X, Kang YQ, Zhang Y. Oxidative stress and hypoxia-induced factor $1 \alpha$ expression in gastric ischemia. World J Gastroenterol. 2011;17(14):1915-1922. doi:10.3748/wjg. v17.i14.1915

23. Fisher EM, Chiu SH, LaManna JC. Changes in gastric mucosa, submucosa, and muscularis IC $\mathrm{pH}$ may herald irreversible tissue injury. Adv Exp Med Biol. 2013;765:59-65.

24. Bali A, Jaggi AS. An integrative review on role and mechanisms of ghrelin in stress, anxiety and depression. Curr Drug Targets. 2016;17 (5):495-507. doi:10.2174/1389450116666150518095650

25. Kang SH, Lee KM, Shin SJ, Lim SK, Hwang JC, Kim JH. Cytomegalovirus gastric ulcer complicated with pyloric obstruction in a patient with ulcerative colitis. Korean J Gastroenterol. 2017;69 (6):359-362. doi:10.4166/kjg.2017.69.6.359

26. Pathan IK, Narendra Babu K, Ashok Kumar KK, et al. Synthesis and gastroprotective evaluation of new chalcone derivatives. Res $J$ Pharmacol Pharmacodynamics. 2013;5(6):325-330.
27. Magierowski M, Magierowska K, Surmiak M, et al. The effect of hydrogen sulfide-releasing naproxen (ATB-346) versus naproxen on formation of stress-induced gastric lesions, the regulation of systemic inflammation, hypoxia and alterations in gastric microcirculation. J Physiol Pharmacol. 2017;68(5):749-756.

28. Peng YL, Liu YN, Liu L, et al. Inducible nitric oxide synthase is involved in the modulation of depressive behaviors induced by unpredictable chronic mild stress. J Neuroinflammation. 2012;9:75. doi:10.1186/1742-2094-9-75

29. Hagag AA, Amin SM, Emara MH, Abo-Resha SE. Gastric mucosal oxidative stress markers in children with helicobacter pylori infection. Infect Disord Drug Targets. 2018;18(1):60-67. doi:10.2174/18715 26517666170502154350

30. Gobert AP, Wilson KT. Polyamine- and NADPH-dependent generation of ROS during Helicobacter pylori infection: A blessing in disguise. Free Radic Biol Med. 2017;105:16-27. doi:10.1016/j. freeradbiomed.2016.09.024

31. Maqbool A, Pauwels A. Cystic fibrosis and gastroesophageal reflux disease. J Cyst Fibros. 2017;16(Suppl 2):S2-S13. doi:10.1016/j. jcf.2017.07.007

32. Carvalho AN, Firuzi O, Gama MJ, Horssen JV, Saso L. Oxidative stress and antioxidants in neurological diseases: is there still hope? Curr Drug Targets. 2017;18(6):705-718. doi:10.2174/1389450 117666160401120514

33. Balasubramanian T, Somasundaram M, Felix AJ. Taurine prevents Ibuprofen- induced gastric mucosal lesions and influences endogenous antioxidant status of stomach in rats. Sci World J. 2004;4:1046-1054. doi:10.1100/tsw.2004.207

34. Da Silva LM, da Silva RCMVAF, Maria-Ferreira D, et al. Vitamin $\mathrm{C}$ improves gastroparesis in diabetic rats: effects on gastric contractile responses and oxidative stress. Dig Dis Sci. 2017;62 (9):2338-2347. doi:10.1007/s10620-017-4632-9

35. Kim TI, Lee YC, Lee KH, et al. Effects of nonsteroidal anti-inflammatory drugs on Helicobacter pylori-infected gastric mucosae of mice: apoptosis, cell proliferation, and inflammatory activity. Infect Immun. 2001;69 (8):5056-5063. doi:10.1128/IAI.69.8.5056-5063.2001

36. Li L, Luo XJ, Liu YZ, et al. The role of the DDAH-ADMA pathway in the protective effect of resveratrol analog BTM-0512 on gastric mucosal injury. Can J Physiol Pharmacol. 2010;88(5):562-567. doi:10.1139/Y10-027

37. Paulrayer A, Adithan A, Lee JH, et al. Aronia melanocarpa (Black Chokeberry) reduces ethanol-induced gastric damage via regulation of HSP-70, NF-кB, and MCP-1 signaling. Int J Mol Sci. 2017;18(6): pii: E1195. doi:10.3390/ijms18061195
Psychology Research and Behavior Management

\section{Publish your work in this journal}

Psychology Research and Behavior Management is an international, peer-reviewed, open access journal focusing on the science of psychology and its application in behavior management to develop improved outcomes in the clinical, educational, sports and business arenas. Specific topics covered in the journal include: Neuroscience, memory and decision making; Behavior modification and management; Clinica applications; Business and sports performance management; Social and developmental studies; Animal studies. The manuscript management system is completely online and includes a very quick and fair peer-review system, which is all easy to use. Visit http://www. dovepress.com/testimonials.php to read real quotes from published authors. 